\title{
APLIKASI WEBSERVER ESP8266 UNTUK PENGENDALI PERALATAN LISTRIK
}

\author{
Rizki Priya Pratama ${ }^{1^{*}}$ \\ ${ }^{1}$ Jurusan Teknik Mekatronika, Politeknik Kota Malang \\ *e-mail: xrizkix2000@gmail.com
}

\begin{abstract}
Abstrak- Penerapan teknologi Internet Of Thing (IoT) telah berkembang pesat, baik digunakan untuk aplikasi di industri maupun rumah tangga. Dengan penerapan teknologi IoT, peralatan listrik rumah tangga dapat dikendalikan secara otomatis melalui web, baik melalui internet maupun jaringan lokal. Web ini dapat menampilkan pengaturan waktu kapan perangkat dinyalakan dan kapan dimatikan. Pembuatan webserver ini menggunakan modul ESP8266 sebagai mikrokontroller utama. Program HTML dan Javascript diubah dan dimasukkan pada program C++ dengan bantuan aplikasi Arduino IDE. Sistem yang dibuat ini, telah disingkronkan dengan NTP server, sehingga waktu pada sistem ini lebih akurat. Disamping itu, RTC DS3231 juga diintegrasikan dalam sistem sehingga jika jaringan internet tidak ada, RTC ini dapat diandalkan. Hasil pengujian yang didapatkan yaitu webserver telah bekerja dengan baik untuk mengendalikan peralatan rumah tangga. Sistem perhitungan dan konversi tabel waktu menjadi bilangan desimal dan begitu sebaliknya dapat diimplementasikan pada webserver.
\end{abstract}

Kata Kunci: ESP8266, DS3231, webserver, IOT, NTP Server

\begin{abstract}
The application of Internet Of Thing technology has developed rapidly, both used for applications in industry and household. With the application of IOT technology, household electrical appliances can be controlled automatically over the web, either through the internet or local networks. This web displays the time settings of when the device is turned on and when it is turned off. Making this web server using the ESP8266 module as main microcontroller. HTML and Javascript programs are modified and included in $C$ ++ programs with the help of the Arduino IDE application. This created system has been synchronized with the NTP server, so the time on the system is more accurate. In addition, RTC DS3231 is also integrated in the system so that if the internet network does not exist, this RTC is reliable. The test results obtained that the webserver has worked well to control household appliances. System calculation and conversion of time tables into decimal numbers can be implemented on the webserver.
\end{abstract}

Keywords: ESP8266, DS3231, webserver, IOT, NTP Server

Copyright @ 2017 INVOTEK. All rights reserved

\section{PENDAHULUAN}

Modul ESP8266 merupakan modul WIFI, yang banyak digunakan untuk aplikasi Internet Of Thing (IOT) seperti mengendalikan aktuator dan membaca sensor. Sistem pengendalian tersebut dapat berbentuk protokol MQTT ataupun webserver yang tertanam dalam memory IC ESP8266 tersebut. Komputer, handphone dan tablet yang dapat mengakses web, dapat mengendalikan aktuator, membaca sensor-sensor.

Penerapan pengendalian tersebut dapat dilakukan pada alat-alat rumah tangga. Alat rumah tangga ini dapat mati dan hidup dengan kontrol dari internet dan dapat dikendalikan secara otomatis dengan web. Web ini menampilkan waktu kapan menyala dan kapan waktu ketika mati. Proses ini akan menghemat penggunaan listrik di rumah, karena pemakaian peralatan rumah tangga sesuai dengan kebutuhan pemilik rumah.

Pada penelitian-penelitian sebelumnya, yang menyangkut komunikasi data pada jaringan, penelitian[1] menggunakan IC ENC28j60 yang mempunyai kapasitas terbatas. Penelitian ini menggunakan jaringan ethernet yang masih menggunakan kabel. Web yang ditampilkan sudah menggunakan pemrograman Javascript. Penelitian [2] menyajikan perancangan kendali relay yang menggunakan mikrokontroler 8051 dengan IC ESP8266. IC ESP8266 digunakan sebagai IC WIFI yang dikendalikan mikrokontroller 8051.

Pada penelitian ini, kami menggunakan IC ESP8266 yang mempunyai kecepatan hingga $160 \mathrm{MHz}$ dan kapasitas memory yang besar. IC ini diprogram langsung kedalamnya, sehingga dapat 
bekerja secara mandiri. Pemrograman webserver pada modul ESP8266 ini, menggunakan bahasa C dengan gabungan bahasa HTML dan Javascript. Bahasa HTML dan Javascript, dimasukkan ke dalam pemrograman bahasa $\mathrm{C}$, sehingga alat ini dapat menampilkan web seperti layaknya komputer server.

\section{TINJAUAN PUSTAKA}

\subsection{Arduino IDE}

Arduino IDE adalah sebuah perangkat lunak yang berfungsi untuk mengembangkan aplikasi mikrokontroler dari proses pembuatan program, kompilasi dan upload. Arduino IDE ini juga dilengkapi dengan terminal serial, sehingga memudahkan pengguna untuk melalukan komunikasi Usart / RS232 ke komputer. Namun, aplikasi ini belum mampu melakukan proses debug secara simulasi maupun secara perangkat keras.

Arduino IDE bersifat Open-source, yang dapat didownload secara langsung pada halaman resminya. Arduino IDE ini mendukung berbagai sistem operasi antara lain Windows, MAC dan Linux. Arduino IDE dilengkapi dengan banyak library $\mathrm{C} / \mathrm{C}++$ sehingga programmer menjadi lebih mudah dan cepat. Pada penelitian ini, peneliti menambahkan library ESP8266-E12, yang telah disediakan pada Board Manager.

\subsection{Modul ESP8266}

ESP8266 merupakan mikrokontroller yang mempunyai fasilitas koneksi WIFI. Karena merupakan mikrokontroller, modul ESP8266 ini mempunyai prosessor dan memory, yang dapat diintegrasikan dengan sensor dan aktuator melalui pin GPIO.

Modul ini mempunyai fitur seperti mendukung standar IEEE $802.11 \mathrm{~b} / \mathrm{g} / \mathrm{n}$, bisa digunakan untuk WiFi direct (P2P), AccesPoint soft-AP, memunyai RAM $81 \mathrm{Mb}$ dan Flash memory $1 \mathrm{Mb}$, kecepatan hingga $160 \mathrm{MHz}$, serta daya keluaran sebesar 19.5 $\mathrm{dBm}[3]$.

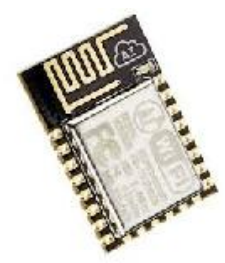

Gambar 1. Modul ESP8266

\subsection{Relay}

Relay adalah komponen listrik yang dioperasikan sebagai saklar. Relay yang digunakan pada penelitian ini adalah HF32F-G. Relay ini dikendalikan dari tegangan DC 5 Volt, yang berjenis SPST. Komponen elektronika ini diperlukan untuk menghubung-matikan peralatan listrik yang bertegangan AC 220Volt. Relay ini dapat dilihat pada Gambar 2.

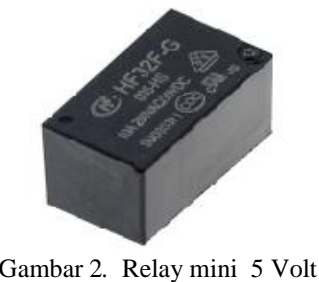

\subsection{RTC DS3132}

Modul RTC yang disajikan pada Gambar 3 merupakan RTC yang murah dan mempunyai tingkat akurasi yang tinggi. RTC ini mempunyai osilator kristal yang terintegrasi dengan pengkompensasi suhu. Modul ini dilengkapi dengan baterry kancing sehingga menjamin ketepatan waktu yang akurat saat daya utama mati[4].

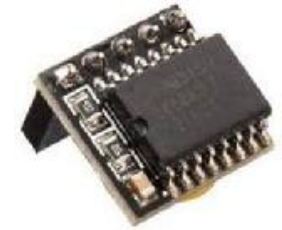

Gambar 3. RTC DS3231

\section{METODOLOGI}

Pada penelitian ini, peneliti ingin menyajikan perancangan hardware dan pemrogaman modul ESP8266 sebagai webserver untuk mengendalikan perangkat elektronik rumah tangga seperti lampu, radio, tape dan TV.

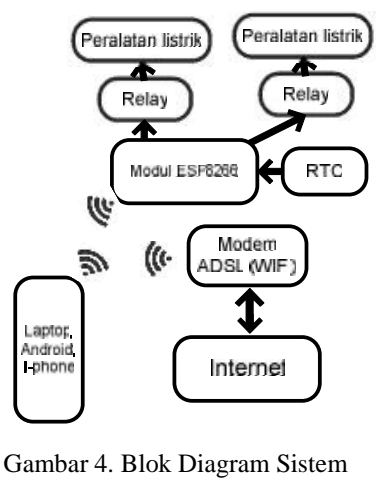

Modul ESP8266 merupakan pengendali utama pada Gambar 4. Modul ini sebagai webserver, pengendali relay dan client dari NTP server. Modul ini diprogram untuk bisa bekerja menjadi webserver dengan atau tanpa terhubung internet. Sekali terhubung internet, modul ini akan meng-update data waktu dari RTC dengan data waktu yang berasal dari NTP server, sehingga waktu yang 
berada di sistem sesuai dengan waktu Intenet. Jika tanpa koneksi internet, data waktu yang tadi disimpan akan tetap akurat berkat RTC DS3231.

Webserver yang berada pada memory modul ini dapat diakses seperti layaknya mengakses web pada komputer. Pengguna dapat menentukan periode bekerjanya suatu peralatan secara otomatis dengan web ini.

Perancangan hardware ini meliputi pemilihan trafo SMPS yang kecil dan low noise, antarmuka dengan RTC DS3231 dan pembuatan driver transistor. Skematik rangkaian dapat dilihat pada Gambar 5 dan foto dapat dilihat pada Gambar 6.
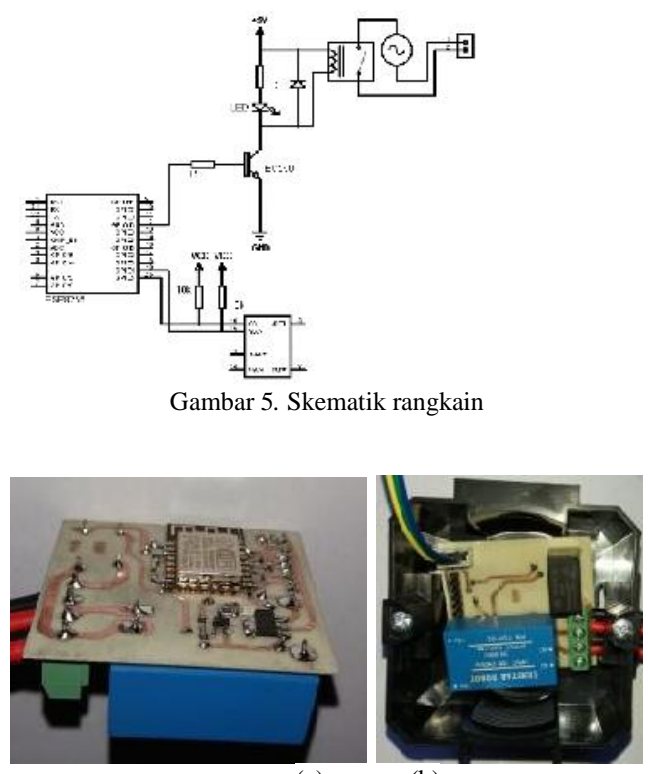

(b)

Gambar 6. Foto perangkat pengendali.

\subsection{Pemrograman ESP8266}

Pada perancangan ini, peneliti membutuhkan packet library ESP8266 antara lain ESP8266WiFi, ESP8266WebServer dan paket library WiFiUdp dan RtcDS3231. ESP8266WiFi digunakan untuk mengaktifkan WIFI sebagai mode Accespoint dan mode Station. ESP8266WebServer digunakan untuk melayani client dalam permintaan akses web [3].

WiFiUdp digunakan untuk komunikasi dengan NTP server dan RtcDS3231 digunakan untuk mengambil data waktu dari DS3231.

ESP8266 ini dapat bekerja di 2 mode Accespoint (AP) maupun mode station. Pada mode AP, ESP8266 dapat terhubung dengan internet dengan interface dari router WIFI. Sedangkan pada mode mode Station, modul ini dapat dapat diakses langsung menggunakan perangkat elektronik seperti HP atau komputer.

Ada 2 mode yang digunakan untuk mengendalikan perangkat rumah tangga, yaitu Aplikasi Webserver.....(Rizki Priya Pratama) manual dan otomatis. Pada mode manual, perangkat langsung dikendalikan hidup dan matinya melalui web. Sedangkan mode otomatis, perangkat hidup mati berdasarkan waktu yang telah diatur melalui web.

ESP8266 menggunakan NTP server untuk proses singkronisasi waktu sistem dengan waktu internet. Proses ini dilakukan setiap beberapa jam sekali, tergantung dari settingan awal. Nilai waktu ini disimpan pada RTC DS3231. RTC DS3231 selain digunakan untuk menyimpan data waktu juga digunakan sistem untuk membandingkan waktu yang di setting dengan waktu yang sebenanya saat mode otomatis aktif. Ketika tidak ada internet atau offline, proses singkronisasi tidak terjadi sehingga tingkat akurasi bergantung pada IC RTC. Akurasi RTC ini hanya mempunyai kesalahan 2 detik pertahun.

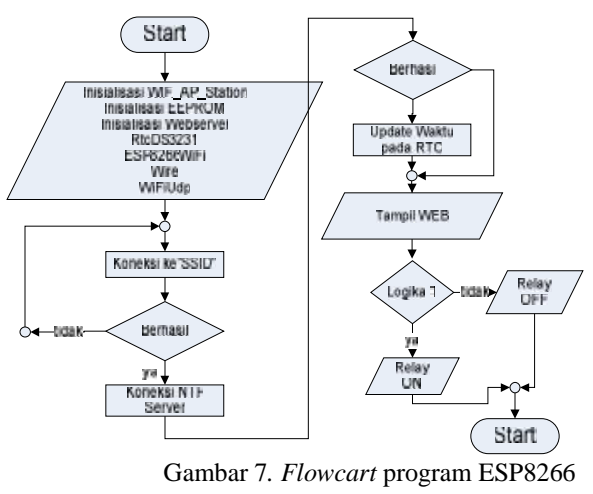

\subsection{Pemrograman Webserver}

Fasilitas yang digunakan untuk memprogram IC ini, adalah Windows 7 dengan aplikasi Arduino IDE. Dalam hal pemrogaman web, peneliti menggunakan progam ADOBE Dreamweaver. Perintah Html dan Javascript dapat dicoba dulu pada aplikasi dreamweaver, baik yang sederhana maupun yang kompleks. Setelah perintah berhasil, barulah perintah HTML dan Javascript dimasukkan ke Arduino IDE.

Javascript dimungkinkan menggunakan fungsi dan procedure. Perintah Javascript ini digunakan untuk menyingkat beberapa pemanggilan procedure yang berkapasitas besar. Sehingga dengan fungsi ini, dapat menghemat berberapa perintah. Instruksi yang digunakan berulang-ulang dapat diringkas menjadi sebuah instruksi pendek yang dipanggil. Tentu ini akan menghemat pemakaian jumlah byte.

Web ini bertugas untuk mematikan dan menyalakan perangkat baik secara manual atau otomatis. Web ini menampilkan tabel yang ditandai dengan warna merah untuk waktu perangkat menyala dan tidak berwarna untuk waktu perangkat 
mati. Pada tabel ini, setiap kolom mewakili durasi sebesar 10 menit. Pemakai menekan urutan kolom jam yang akan menyala atau mati dengan menggunakan mouse.

Web ini dibuat dengan gabungan bahasa HTML dan Javascript. Program Javascript dan HTML bertugas untuk membentuk tabel waktu. Program Javascript dibuat untuk membentuk tabel waktu mulai jam 00.00 hingga jam 23.59. Tabel ini dibagi - bagi, setiap kolom mewakili 10 menit. Kemudian setiap 3 jam dari tabel tersebut mewakili 18 bit data seperti pada Gambar 8.

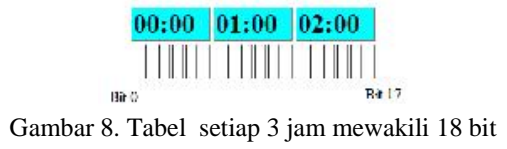

Berikut cuplikan program dari pembuat tabel dan pengaturan kolom 10 menitan (Gambar 8).

\subsection{Perancangan Driver Relay}

Pada perancangan driver relay (Gambar 9), arus yang dibutuhkan untuk mengaktifkan sebuah relay adalah $20 \mathrm{~mA}$ dengan tegangan 5 volt. Driver relay digunakan untuk mengendalikan peralatan rumah tangga dengan tegangan 220 volt. Driver relay bekerja dari kendali pin GPIO10 ESP8266. Jika kondisi pin berlogika satu, maka relay akan hidup dan peralatan listrik / lampu menyala. Jika pin berlogika nol maka relay mati dan peralatan listrik / lampu mati.

Dari pengukuran arus diketahui bahwa yang dibutuhkan oleh relay yaitu $0,02 \mathrm{~A}(20 \mathrm{~mA})$ dengan tegangan 5 Volt. Pada BC550 mempunyai $\beta=$ 100[5] sehingga :

$$
i b=\frac{20 m A}{100}
$$

$$
=0,2 \mathrm{~mA}
$$

Jadi, arus minimal yang dapat digunakan untuk mengaktifkan relay adalah $0,2 \mathrm{~m} A$. Arus maksimal

setiap pin pada ESP8266 adalah $12 \mathrm{~mA}$ dengan tegangan 3.3 volt. Dengan loop didapatkan :

$$
V_{G P I O 10}=i b . R 1+0,7
$$

Dari perhitungan (1), ib $=0,2 m A$ dan

$$
R 1=21,5 k
$$

Didapatkan hasil R1 adalah 21,5k. Nilai resistor tersebut adalah nilai maksimal yang dapat digunakan. Jika lebih dari $14 \mathrm{k}$ maka relay kekurangan arus dan akibatnya relay tidak bekerja. Maka pada perancangan ini, kita menggunakan resistor $18 \mathrm{k}$.

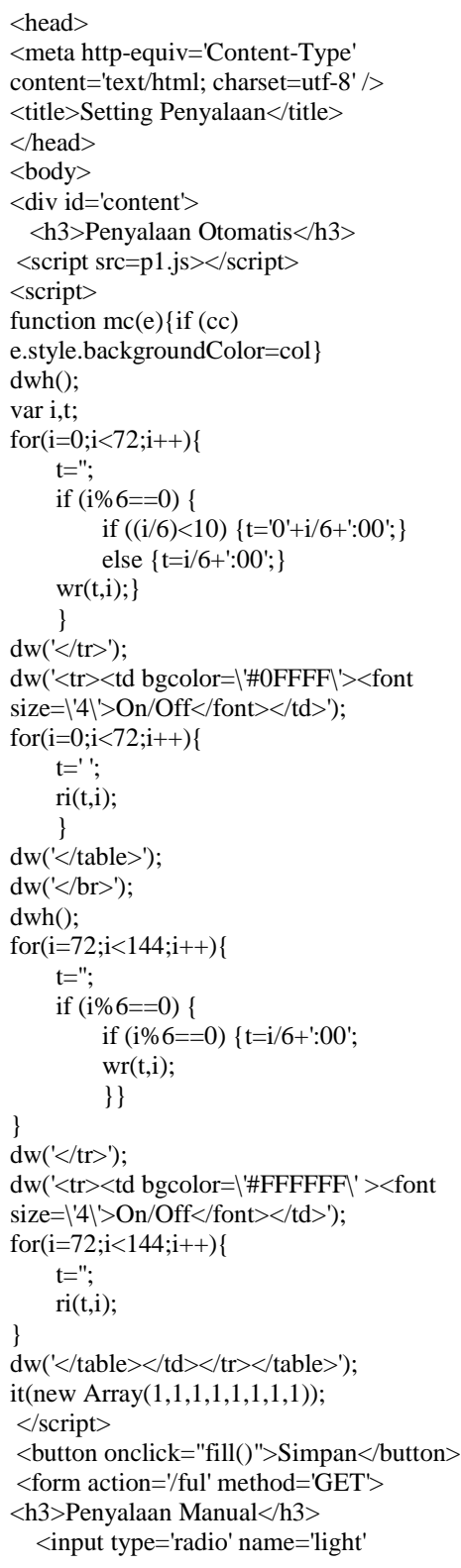

Gambar 9. Potongan program pembuat tabel waktu

didapatkan perhitungan :

$$
5=0,2 m A \cdot R 1+0,7
$$

$$
R 1=\frac{5-0,7}{0,2 m}
$$




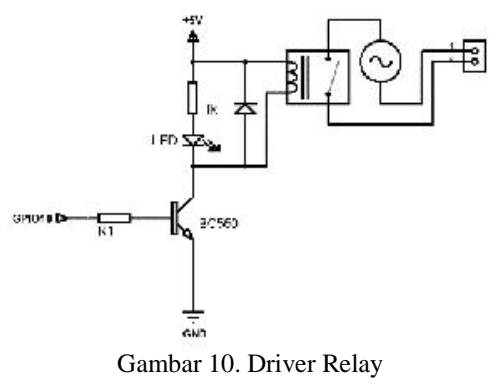

IV. HASIL DAN PEMBAHASAN

\subsection{Pengujian Waktu RTC dan NTP Server}

Pada pengujian ini, kami membandingkan antara waktu RTC DS3231 dan waktu NTP Server dengan menggunakan serial monitor Arduino IDE. Waktu pengujian dilakukan tanggal 25 Oktober 2017 jam 20.34 .

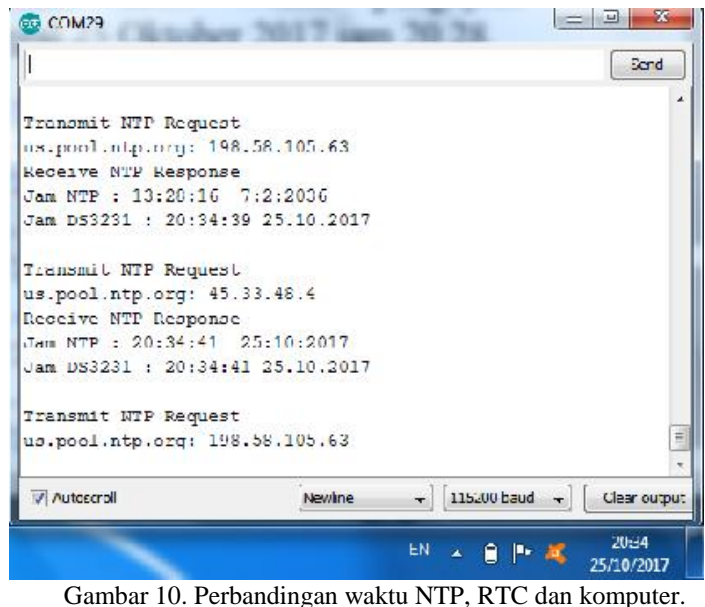

Perbandingan ketiga waktu NTP, RTC dan komputer mendapatkan hasil yang sama dapat dilihat pada Gambar .

\subsection{Pengujian Webserver}

Perangkat listrik dapat menyala atau mati dikendalikan oleh web baik secara manual atau secara otomatis. Pada Gambar 11 terlihat bahwa perangkat listrik akan menyala pada jam 22.30 00.00 secara otomatis.

Pengaturan waktu dilakukan dengan memberikan tanda merah pada setiap kolom. Pemberian warna merah menandakan bahwa kolom tersebut berlogika 1. Dari hasil pengujian didapatkan hasil bahwa konversi ke dalam bilangan desimal sudah tepat. Hal ini dapat dilihat pada Tabel 1 .

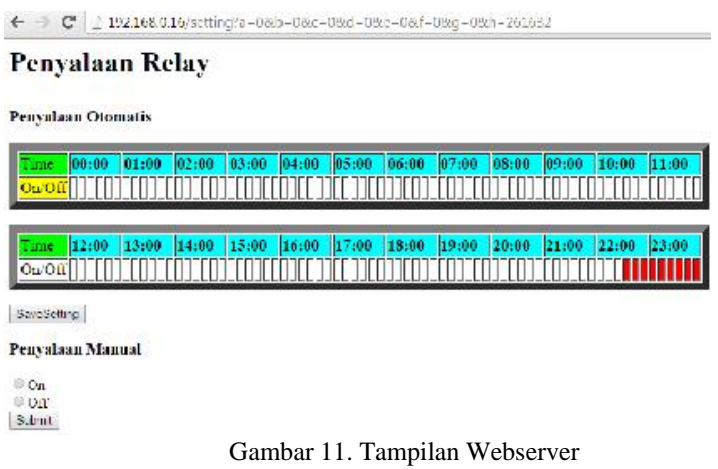

Tabel 1. Konversi tabel penyalaan dalam desimal

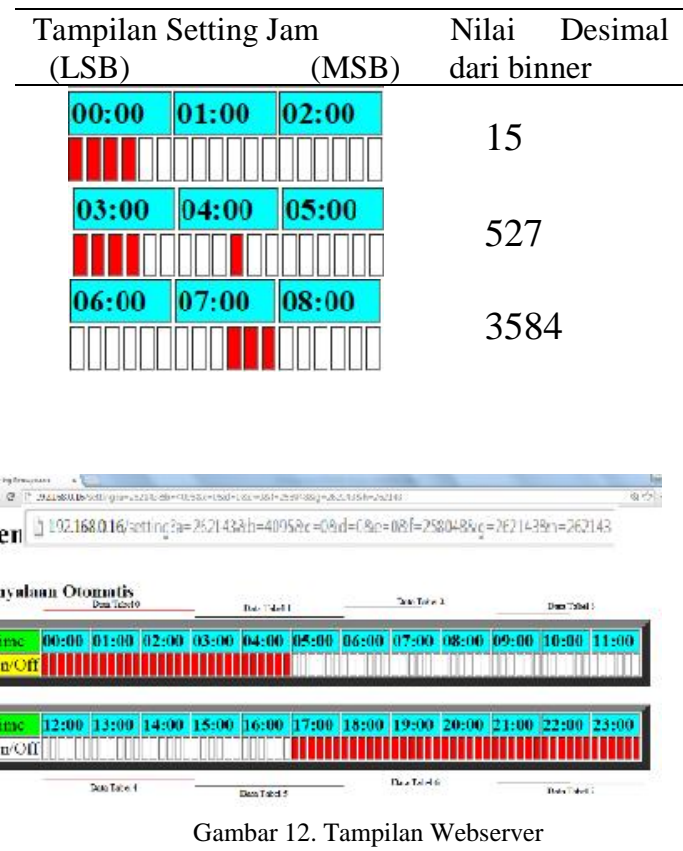

Pada Gambar 12, terdapat alamat yang panjang yaitu http://192.168.0.16/ setting? $\mathrm{a}=249855 \& \mathrm{~b}=4095 \& \mathrm{c}=0 \& \mathrm{~d}=0 \& \mathrm{e}=72 \& \mathrm{f}=25$ $8048 \& \mathrm{~g}=262143 \& \mathrm{~h}=262143$. Nilai $\mathrm{a}=249855$ merupakan nilai dari data tabel 0 , nilai $b=4095$ adalah nilai data tabel $1 \mathrm{dsb}$. Nilai-nilai desimal dari a,b,c,d,e,f dan g didapatkan dari kolom-kolom pada tabel tersebut. Kemudian di dalam ESP8266, nilai desimal tersebut disimpan dan dibandingkan dengan waktu. Nilai tadi disimpan dalam EEPROM ESP8266. Jika sistem ingin menampilkan laman "penyalaan relay otomatis", maka sistem akan mengambil data EEPROM tersebut, diproses menjadi kolom-kolom berwarna merah.

\subsection{Pengujian driver relay}

Pengujian rangkaian driver relay ini perlu dilakukan supaya perangkat listrik dapat dikontrol mati dan hidup dengan memberikan logika 1 dan 0.

Pada Tabel 2 ditunjukkan bahwa pada saat transistor aktif (saturasi) tegangan vbe $=0,7$ volt, 
vce $=115,7 \mathrm{mV}$ dan tegangan relay $=4,61 \mathrm{~V}$. Sedangkan pada saat transistor tidak bekerja (cutt off) tegangan vbe $=0$ volt, vce $=4,94$ volt dan tegangan relay $=0$ volt .

Tabel 2. Pengujian nilai tegangan transistor dan relay.

\begin{tabular}{ccccc}
\hline $\begin{array}{c}\text { Percobaan } \\
\text { ke }\end{array}$ & \multicolumn{4}{c}{ Logika 1 } \\
& $\begin{array}{c}\text { Vbe } \\
\text { (Volt) }\end{array}$ & $\begin{array}{c}\text { Vce } \\
\text { (Volt) }\end{array}$ & $\begin{array}{c}\text { Vrelay } \\
\text { (Volt) }\end{array}$ & $\begin{array}{c}\text { LED } \\
\text { (On/off) }\end{array}$ \\
\hline 1 & 0,688 & $115,7 \mathrm{mV}$ & 4,61 & on \\
2 & 0,695 & $113,7 \mathrm{mV}$ & 4,62 & on \\
3 & 0,696 & $111,7 \mathrm{mV}$ & 4,58 & on \\
4 & 0,694 & $115,7 \mathrm{mV}$ & 4,59 & on \\
5 & 0,755 & $117,7 \mathrm{mV}$ & 4,57 & on
\end{tabular}

\section{KESIMPULAN}

Pemrograman web selain dapat dilakukan menggunakan komputer, juga dapat dilakukan dengan mikrokontroller. ESP8266 diprogram layaknya seperti webserver pada komputer. Program Javascript dan HTML yang disimpan pada ESP8266 selaku mini webserver dapat menampilkan tabel waktu untuk mengontrol peralatan listrik. Nilai-nilai waktu dapat dikonversi dari tabel waktu menjadi nilai desimal dan dapat disimpan pada memory ESP8266. Masalah kepresian waktu merupakan hal pokok dari sistem ini ditunjukkan dengan waktu NTP server dan RTC menunjukan hasil yang sama. Sedangkan untuk driver relay, yang akan mengendalikan peralatan listrik, tegangan vce transistor 0,11 volt saat relay hidup. Transistor dalam keadaan saturasi.

\section{DAFTAR PUSTAKA}

[1] Pratama, Rizki Priya,"Desain Sistem Kendali Lampu Pada Rumah dengan Mini Webserver AVR", in ELTEK journal, Vol.11, No.1, Malang : Polinema ,2013, pp 1-16.

[2] B. Anilkumar, N. Lakshmidevi, and P. Choudary, "Home Automation through Smart Phone using ESP8266 Wi-Fi Module by IOT," vol. 3, no. 4, pp. 17-21, 2017

[3] ESP8266 - 12E Datasheet, https://www.adafruit.com/datasheets/ESP8266_Spe cifications_English.pdf

[4] A. Pawar, G. Lohiya, A. Thumbre, D. Prajapati, and R. Kadu, "Environment Control and Measurement System using Internet of Things," vol. 7, no. 4, pp. 1033-1038, 2016.

[5] Malvino A.P., "Transistor", in Prinsip-prinsip Elektronika Jilid 1, Jakarta : Penerbit Erlangga , 1985

[6] Kumar. Manu, Ekta, Agarwal. Shruti, Gaur dan Gupta, Yashdeep, "Internet Based Home Automation. International Journal of Research and Development Organization", in Journal of Electronics and Computer Science Vol. 2, Issue 8, Aug. 2015.

\section{Biodata Penulis}

Rizki Priya Pratama, ST, MT, M.Sc, menempuh kuliah S1 di Teknik Elektro Universitas Brawijaya dan S2 DDIP di Universitas Indonesia jurusan Kontrol Industri, dan Universite' D’Anger, Perancis. Penulis dilahirkan di Pasuruan, 23 Juni 1981. 